\title{
Morphological changes of the jejunal mucosa in protracted diarrhea and their correlation with disease duration, weight loss and serum albumin levels
}

L.A. Péret-Filho ${ }^{1}$

G. Brasileiro-Filho ${ }^{2}$ and F.J. Penna ${ }^{1}$

\author{
'Departamento de Pediatria and ${ }^{2}$ Departamento de Anatomia Patológica, \\ Faculdade de Medicina, Universidade Federal de Minas Gerais, \\ Belo Horizonte, MG, Brasil
}

\footnotetext{
Correspondence

L.A. Péret-Filho

Departamento de Pediatria

Faculdade de Medicina, UFMG

Av. Alfredo Balena, 190, 4ํandar

30130-100 Belo Horizonte, MG

Brasil

Fax: 55 (031) 224-7041

Research supported by CPq-UFMG, $\mathrm{CNPq}$ and FAPEMIG.

This work is part of a Master's thesis presented by L.A. Péret-Filho to the Curso de Medicina Tropical, Faculdade de Medicina, UFMG, Belo Horizonte, MG, Brasil.
}

Received January 20, 1997 Accepted July 21, 1997

\begin{abstract}
The pathogenesis of protracted diarrhea is multifactorial. In developing countries, intestinal infectious processes seem to play an important role in triggering the syndrome. Thirty-four children aged 1 to 14 months, mean 6.5 months, with protracted diarrhea were studied clinically and in terms of small intestinal mucosal morphology. Mild, moderate or severe hypotrophy of the jejunal mucosa was detected in $82 \%$ of cases, and mucosal atrophy was observed in $12 \%$. The intensity of the morphological changes of the jejunal mucosa correlated negatively with serum albumin levels. No correlation was detected between mucosal grading and duration of diarrhea or between mucosal grading and weight reported as percentile. After nutritional support was instituted, serial jejunal biopsies were obtained from 12 patients: five patients submitted to parenteral nutrition for 7 to 38 days, mean 17 days, and 7 patients receiving a hypoallergenic oral diet (semi-elemental formula, 3; chicken formula, 3; human milk, 1). In seven cases $(58 \%)$ a progressive increase in villus height and a decrease in the number of inflammatory cells were noted. Recovery of the morphologic pattern was accompanied by clinical improvement in all patients.
\end{abstract}

Key words - Protracted diarrhea

- Biopsy

- Jejunal mucosa

- Serum albumin

\section{Introduction}

Protracted diarrhea is a clinical syndrome lasting 14 days or more which mainly affects infants during the first months of life, causing water-electrolyte lability and progressive nutritional deterioration.

Structural lesions of the small intestinal mucosa are important components of the syndrome and seem to contribute in a significant manner to the worsening of clinical signs and symptoms. These lesions are caused by several factors, among them intolerance to dietary protein, malnutrition and bacterial overgrowth in the small intestine. In Brazil, intestinal infectious processes seem to play an important role in triggering the syndrome. The presence of bacteria in patients with protracted diarrhea, especially classic enteropathogenic $E$. coli, has been reported $(1,2)$. The serotypes detected have the property of adhering to the epithelium and provoking important morphological and functional changes in the small intestine. 
Greene et al. (3) reported jejunal changes in 16 patients with protracted diarrhea, all of them with significant mucosal villus hypotrophy. After parenteral feeding and/or an enteral diet consisting of semi-elemental formulas, the lesions were fully reversed within 18 days, on average, from the beginning of nutritional treatment. In contrast, in a study of jejunal biopsies from children with the same condition, Rossi et al. (4) detected varying degrees of jejunal mucosa hypotrophy that persisted for 6 months in $16(70 \%)$ of their 23 patients. Goldegard and Vanderhoof (5) did not detect a correlation between severity of intestinal mucosal lesions and prognosis in 19 children.

Few studies have been conducted in tropical countries with the objective of analyzing the reversal of jejunal mucosal abnormalities by the treatment instituted in infants with protracted diarrhea. In a study of 20 children with persistent diarrhea in Gambia, Sullivan et al. (6) did not observe an improvement in villus architecture or reduction of the inflammatory infiltrate after one month of treatment with a high proteincalorie diet, despite the occurrence of weight gain and normalization of serum albumin levels.

The objective of the present study was to investigate the morphological aspects of the jejunal mucosa of infants with protracted diarrhea from low socioeconomic level families and to correlate serum albumin levels, body weight and duration of diarrhea with the extent of jejunal mucosal damage.

\section{Patients and Methods}

Thirty-four children with protracted diarrhea, characterized by three or more daily evacuations, lasting two weeks or more and with water-electrolyte lability were admitted to the Pediatric Ward of the University Hospital, UFMG, from January 1980 to December 1993. A total of 49 jejunal biopsies were obtained from 34 patients (18 girls and 16 boys aged 1 to 14 months; mean, 6.5 months) (Table 1).

Most of the patients were from the outskirts of the city of Belo Horizonte, where they lived under precarious basic sanitation conditions. All patients were transferred to our Hospital from others after failure of conservative treatment.

The jejunal biopsies were obtained 15 to 127 days after the onset of diarrhea (mean duration, 53 days), after the parents gave informed consent. The 34 patients were equilibrated in terms of water-electrolyte balance and acid-base balance and had been fasting for at least $3 \mathrm{~h}$. Crosby-Kugler (pediatric model, 1975), Carey or Watson capsules were used. Patients were intubated as described by Toccalino and O'Donnell (7). When a signal of the presence of the capsule in the duodenum was obtained in terms of bile flow or spontaneous progression of the tube, a single abdominal X-ray was obtained to localize it. The biopsy was performed when the capsule was close to the Treitz angle. The fragment obtained was stretched on porous paper previously soaked in $10 \%$ formalin, with the villi looking up. After fixation for 6 to $18 \mathrm{~h}$, the fragment was examined with a dissection microscope for mesoscopic evaluation and selection of the most representative areas for histological analysis, and routinely processed for histopathology. Histological sections ( $6 \mu \mathrm{m}$ thick) perpendicular to the mucosal surface were stained with hematoxylin-eosin (HE) and periodic acid Schiff (PAS).

Histological analysis was performed according to the criteria proposed by others (810 ), with small modifications. The material was scored as follows: grade 0 or normal: high and thin villi are present throughout the extension of the fragment examined and correspond to 2.5 to 3 times the depth of the crypts. Columnar enterocytes with nuclei located in the basal region, acidophilic cytoplasm and a clearly visible brush border are present. A small number of leucocytes are 
present in the lamina propria.

Grade I or mild hypotrophy: villus height is slightly decreased, corresponding to 1.5 to 2 times the crypt length. A discrete flattening of enterocytes and a larger number of mononuclear cells are visible in the lamina propria.

Grade II or moderate hypotrophy: the villi are even shorter and their height does not exceed the depth of the crypts. The enterocytes are more flattened and the brush border may be absent throughout the entire mucosa. Marked infiltration of inflammatory cells is often observed in the lamina propria. The number of intraepithelial lymphocytes may be increased.

Grade III or severe hypotrophy: there is an inversion of the villus/crypt ratio due to pronounced shortening and widening of the villi, which appear only as rudimentary structures. The mononuclear infiltrate in the lamina propria is increased.

Grade IV or atrophic pattern: this stage corresponds to the maximum degree of mucosal atrophy, characterized by the absence of villi. The enterocytes become flattened and lose the brush border. A large number of mononuclear cells are frequently detected in the lamina propria, generally coexisting with increased numbers of intraepithelial lymphocytes. Edema of the lamina propria is sometimes observed.

Serum albumin levels were determined in 26 patients. Samples were collected $24 \mathrm{~h}$ before, on the same day, or at most on the day after the jejunal biopsy. Albumin was measured by the biuret method and the results are reported as $\mathrm{g} / \mathrm{dl}$. The duration of diarrhea (three or more evacuations daily) was determined on the basis of information provided by the parents or persons responsible and recorded as number of days. Body weight was evaluated in terms of percentile for age using the computer software developed by Jordan (11).

The total parenteral nutrition was composed of amino acids and lipids, which were provided initially at $1.0 \mathrm{~g} \mathrm{~kg}^{-1} \mathrm{day}^{-1}$ and progressively increased for 7 days to $2.5 \mathrm{~g} \mathrm{~kg}^{-1}$ day $^{-1}$ and $3.0 \mathrm{~g} \mathrm{~kg}^{-1}$ day $^{-1}$, respectively. All solutions were mixed in $10 \%$ dextrose. Electrolytes and other additives were as follows: $30 \mathrm{mEq} / \mathrm{l} \mathrm{NaCl}, 25 \mathrm{mEq} / \mathrm{l} \mathrm{K}{ }^{+}, 2 \mathrm{mEq} / \mathrm{l} \mathrm{Mg}{ }^{2+}$, $15 \mathrm{mEq} / \mathrm{l} \mathrm{Ca}{ }^{2+}, 10 \mathrm{mEq} / \mathrm{K} \mathrm{KH}_{2} \mathrm{PO}_{4}$, multivitamin preparation (Polivit $\mathrm{A}^{\circledR}-10 \mathrm{ml}$ ) and oligoelements (Politrace ${ }^{\circledR}-0.2 \mathrm{ml} / \mathrm{kg}$ ).

The hypoallergenic diet was composed of semi-elemental formula (Alfaré ${ }^{\circledR}$ ), 15\% dilution, $52 \mathrm{~g}$ hydrolized whey protein, lipids (17.2 g triglycerides, $10.3 \mathrm{~g}$ milk fat, 6.9 $\mathrm{g}$ corn oil, $1.5 \mathrm{~g}$ biotin), carbohydrates (67.0 $\mathrm{g}$ dextrin-maltose, $9.0 \mathrm{~g}$ potato wheat, $1.5 \mathrm{~g}$ lactose), vitamins, minerals and oligoelements, and water added to make $1000 \mathrm{ml}$. Calories: $72 / 100 \mathrm{ml}$.

The chicken formula was composed of $150 \mathrm{~g}$ cooked chicken, $40 \mathrm{~g}$ corn oil, $80 \mathrm{~g}$ dextrin-maltose, $0.5 \mathrm{~g} \mathrm{NaCl}, 2 \mathrm{~g} \mathrm{CaCO}_{3}$, vitamins (Protovit ${ }^{\circledR}$ - 15 drops) and cold water to make $1000 \mathrm{ml}$. Calories: 70/100 ml.

The study was approved by the Hospital Ethics Committee and consent was obtained from the parents.

Data were analyzed statistically by the chi-square test for comparison of the frequencies observed, by the Pearson correlation for comparison between variables, by simple concrete adjusted linear regression, and by the regression determination coefficient $\mathrm{R}^{2}$, with the level of significance set at $\mathrm{P}<0.05$.

\section{Results}

Table 1 shows the age, sex and serum albumin levels of the infants, as well as the grading of the jejunal mucosal pattern. In two of the 34 biopsies examined (5.9\%) the villus pattern was considered to be normal. In 16 patients the morphologic changes were irregular, with some areas more involved than others, and the material was classified according to the highest grade. In 12 cases (35.3\%) there was mild villus hypotrophy, 
usually irregular, with no changes in enterocytes or in cellularity of the lamina propria. Villus hypotrophy was moderate in 12 cases $(35.3 \%)$ and severe in 4 cases (11.8\%). Two patients presented areas of moderate hypotrophy side by side with areas of marked hypotrophy. In four cases $(11.8 \%)$ there was atrophy of the villi. In these last three groups of patients (a total of 20), in addition to villous changes there were loss of the brush border, decreased enterocyte height, crypt elongation relative to the villus height and increased cellularity of the lamina propria, all of these phenomena being more marked in the last group. The brush border was usually absent or showed irregular distribution in the mucosa with marked hypotrophy or atrophy, always in the presence of

Table 1 - Clinical and laboratory characteristics of patients with protracted diarrhea.

${ }^{*}$ According to Jordan (11). ${ }^{*}$ Modified from Shenk and Klipstein (9). D, Death; C, cure.

\begin{tabular}{|c|c|c|c|c|c|c|c|c|}
\hline Patient & $\begin{array}{c}\text { Age } \\
\text { (months) }\end{array}$ & Sex & $\begin{array}{l}\text { Weight } \\
(\mathrm{kg})\end{array}$ & Percentile* & $\begin{array}{c}\text { Serum } \\
\text { albumin (g/dl) }\end{array}$ & $\begin{array}{c}\text { Duration of } \\
\text { diarrhea (days) }\end{array}$ & $\begin{array}{c}\text { Extent of } \\
\text { mucosal atrophy** }\end{array}$ & Outcome \\
\hline 1 & 3.0 & M & 4.00 & 1.86 & - & 63 & I & D \\
\hline 2 & 1.5 & $\mathrm{~F}$ & 2.50 & 0.20 & - & 52 & I & D \\
\hline 3 & 7.0 & M & 5.70 & 0.32 & - & 41 & III & D \\
\hline 4 & 6.0 & M & 4.54 & 0.04 & - & 53 & II & C \\
\hline 5 & 6.0 & M & 3.70 & 0.00 & 3.0 & 44 & II & C \\
\hline 6 & 14.0 & $\mathrm{~F}$ & 5.37 & 0.00 & 1.9 & 60 & IV & C \\
\hline 7 & 6.5 & $\mathrm{~F}$ & 5.90 & 3.89 & 2.4 & 60 & IV & C \\
\hline 8 & 3.0 & $\mathrm{~F}$ & 3.60 & 0.79 & 3.6 & 127 & I & C \\
\hline 9 & 4.0 & $\mathrm{~F}$ & 3.33 & 0.03 & 2.5 & 69 & I & C \\
\hline 10 & 6.5 & M & 3.80 & 0.00 & 3.5 & 15 & II & C \\
\hline 11 & 9.0 & $\mathrm{~F}$ & 5.10 & 0.02 & 3.0 & 52 & I & C \\
\hline 12 & 6.0 & $F$ & 4.10 & 0.02 & 3.0 & 55 & 0 & C \\
\hline 13 & 10.0 & M & 5.60 & 0.00 & 3.3 & 100 & I & C \\
\hline 14 & 9.0 & M & 5.95 & 0.04 & 1.9 & 34 & IV & C \\
\hline 15 & 3.5 & $\mathrm{~F}$ & 2.70 & 0.00 & 2.4 & 23 & III & C \\
\hline 16 & 2.0 & M & 2.50 & 0.09 & 2.7 & 15 & I & C \\
\hline 17 & 6.0 & M & 5.85 & 2.04 & - & 32 & II & C \\
\hline 18 & 10.0 & M & 7.80 & 3.80 & - & 20 & II & C \\
\hline 19 & 7.0 & $\mathrm{~F}$ & 3.70 & 0.00 & 2.4 & 113 & I & D \\
\hline 20 & 1.0 & $\mathrm{~F}$ & 2.05 & 0.06 & 2.8 & 17 & I & C \\
\hline 21 & 5.0 & $\mathrm{M}$ & 4.20 & 0.09 & 2.0 & 42 & II & C \\
\hline 22 & 8.0 & $\mathrm{M}$ & 5.50 & 0.03 & 1.8 & 39 & II & C \\
\hline 23 & 7.5 & $\mathrm{M}$ & 6.42 & 1.30 & 2.6 & 47 & III & C \\
\hline 24 & 4.0 & $\mathrm{~F}$ & 4.16 & 0.88 & 2.0 & 116 & I & D \\
\hline 25 & 4.5 & $\mathrm{M}$ & 3.50 & 0.02 & 1.9 & 112 & IV & C \\
\hline 26 & 2.5 & $\mathrm{~F}$ & 3.92 & 5.56 & 3.1 & 52 & II & C \\
\hline 27 & 15.0 & $\mathrm{~F}$ & 7.20 & 0.32 & - & 35 & 1 & C \\
\hline 28 & 4.5 & $\mathrm{~F}$ & 3.39 & 0.01 & 1.0 & 23 & III & D \\
\hline 29 & 11.0 & $\mathrm{M}$ & 6.50 & 0.04 & 2.0 & 63 & II & C \\
\hline 30 & 6.0 & $\mathrm{M}$ & 7.10 & 22.24 & - & 47 & 0 & C \\
\hline 31 & 14.0 & $\mathrm{~F}$ & 6.30 & 0.03 & 3.8 & 23 & II & C \\
\hline 32 & 6.0 & $\mathrm{~F}$ & 3.91 & 0.01 & 2.4 & 60 & II & C \\
\hline 33 & 3.0 & $\mathrm{~F}$ & 4.37 & 8.36 & 3.7 & 56 & I & C \\
\hline 34 & 7.0 & $\mathrm{~F}$ & 5.43 & 0.59 & 2.0 & 40 & II & C \\
\hline
\end{tabular}


cuboidal or flattened enterocytes. The number of intraepithelial lymphocytes increased with decreasing villus size. A jejunal biopsy was intensely parasitized with Cryptosporidium sp. No other parasites were detected upon histological examination.

Twelve patients were submitted to serial biopsies at intervals of 7 to 20 days, with a mean of 13 days and a median of 14 days. All of them showed clinical improvement on the occasion of the second biopsy. Five of them had intense mucosal lesions (grade III or IV) and were submitted to total parenteral nutrition. Four of these patients presented a marked improvement of the morphological picture after approximately 15 days, but one continued to present the same lesions after 38 days of follow-up (Figure 1). After 14 months of follow-up, this last patient, 15.5 months old at the time, started to tolerate cow's milk. An additional jejunal biopsy was not obtained because the parents refused it. The remaining seven patients were treated with an oral diet (semi-elemental formula, human milk or chicken formula). Although their lesions were less severe than those of infants treated with parenteral nutrition, 4 of them presented a less marked improvement in the morphological pattern within the same period of time (a mean period of 13 days of treatment) (Figure 2). The patients submitted to parenteral nutrition received a caloric amount similar to that of the patients receiving an oral diet $(80 \mathrm{kcal}$ $\mathrm{kg}^{-1}$ day $^{-1}$ and $2.5 \mathrm{~g}$ amino acids $\mathrm{kg}^{-1}$ day $^{-1}$ at the end of the first week). Improvement of the histological pattern of the jejunal mucosa was accompanied by clinical improvement in all patients.

There was a negative correlation between serum albumin levels and mucosal grading $(\mathrm{r}$ $=-0.501, \mathrm{P}<0.005)($ Figure 3$)$. No correlation was detected between mucosal grading and duration of diarrhea $(\mathrm{r}=-0.131, \mathrm{P}>0.05)$ or between mucosal grading and patient weight reported as percentile $(r=-0.100$, $\mathrm{P}>0.05)$.

\section{Discussion}

The present study confirms that protracted diarrhea is a severe clinical condition causing profound changes in the nutritional status of the patients. Of the 34 cases described, only one had normal weight, whereas the remaining 33 presented a considerably marked nutritional deficiency.

Analysis of the jejunal biopsies showed morphological alterations in most cases, with

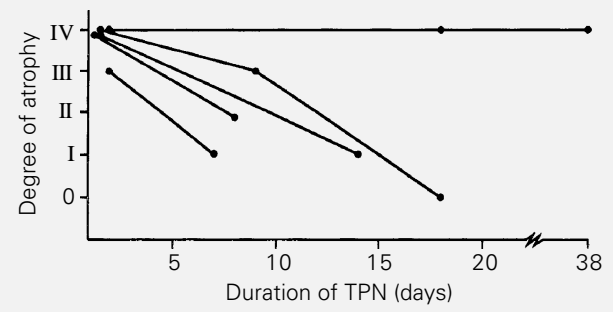

Figure 1 - Evolution of jejunal mucosal morphology in 5 infants with protracted diarrhea submitted to total parenteral nutrition (TPN).

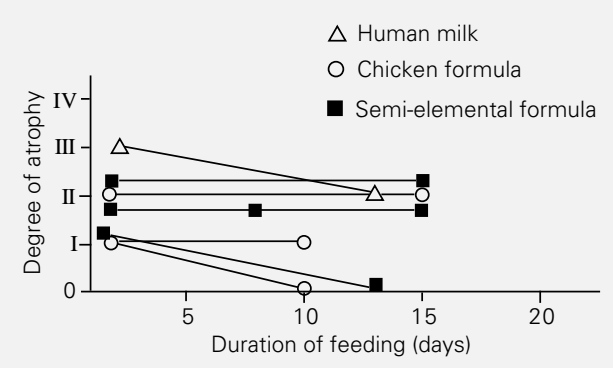

Figure 2 - Evolution of jejunal mucosal morphology in 7 infants with protracted diarrhea treated with an oral diet.

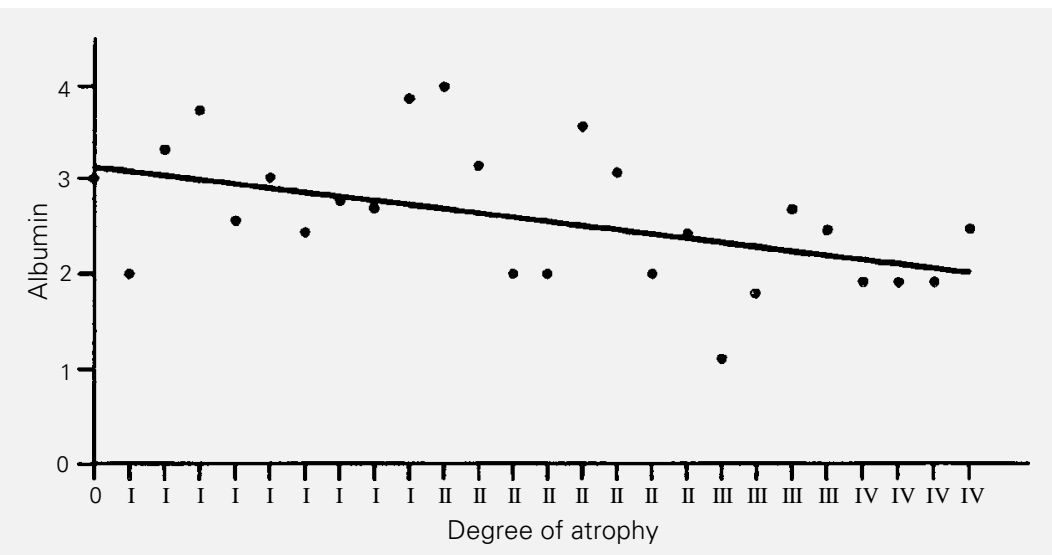

Figure 3 - Serum albumin level vs degree of jejunal mucosal atrophy in 26 infants with protracted diarrhea. $r=-0.501, P<0.005$. 
only two patients (5.0\%) showing a normal histological pattern. Twenty patients $(58.8 \%)$ presented moderate or severe morphological changes. The lesions were nonspecific in all cases and were similar to those reported for marasmus patients (8) and for children with kwashiorkor (12).

Total villus atrophy similar to that occurring in celiac disease was detected in four patients, a finding similar to that observed in patients with kwashiorkor (13). A more detailed comparative examination, however, showed that normal mucosal thickness is preserved in patients with celiac disease, whereas the mucosa is thinner in malnourished children with protracted diarrhea. Only one of the patients with complete villus atrophy and with all of the other characteristics of celiac disease described above was later confirmed to have celiac disease during follow-up.

The dietary treatment of these patients (parenteral nutrition or semi-elemental diets) resulted in an improved morphological pattern of the intestinal mucosa in most of them. The vitamins and trace elements (zinc in particular) provided by parenteral nutrition may explain, at least in part, the better response of these patients compared to those receiving only the semi-elemental diet.

However, the claim that parenteral nutrition produces a better response than a semielemental formula cannot be made from our data since at the beginning of the study the children receiving the two treatments had different degrees of histological abnormality.

The negative correlation between degree of intestinal mucosal lesion and serum albu- min levels was predictable. Numerical factors may explain the lack of statistical correlation between body weight and mucosal grading. Since almost all patients had suffered a considerable weight loss (all but one were below the 3rd percentile), the difference in nutritional deficiency among them was quite small, since all were severely emaciated. Thus, the numerical interval among them was small, making it impossible to detect a statistical relationship between these two variables, although it was clear that $94 \%$ of the infants presented morphological mucosal changes and $97 \%$ were nutritionally deficient.

The absence of a correlation between duration of diarrhea and intensity of morphological lesions of the intestinal mucosa indicates once again that functional intestinal changes are not always related to the degree of structural involvement of the mucosa. In this respect, it is possible that moderate or severe morphological changes of the mucosa did not impair nutrient digestion or absorption in some patients, whereas mild or absent changes were accompanied by profound functional modifications in other patients, resulting in water, electrolyte and nutrient malabsorption. This possibility may also explain in part the lack of correlation between weight loss and intensity of mucosal changes.

The intensity of intestinal mucosal atrophy explained the low serum albumin levels detected in $25 \%$ of the patients $\left(\mathrm{R}^{2}\right)$. The explanation for the remaining $75 \%$ might be due to other causes such as insufficient protein-calorie intake, severe associated infections, etc. 


\section{References}

1. Fagundes Neto $U$, Trabulsi LR \& Patrício FRS (1988). Diarréia protraída: a importância dos agentes enteropatogênicos na sua gênese e fisiopatologia. Jornal de Pediatria, 64: 237-241.

2. Bhan MK, Khoshoo V, Sommerfelt $H$, Pushker R, Sorawal S \& Srivastava R (1989). Enteroaggregative "Escherichia coli" and "Salmonella" associated with nondysenteric persistent diarrhea. Pediatric Infectious Disease Journal, 8: 499-502.

3. Greene HL, McCabe DR \& Merenstein GB (1975). Protracted diarrhea and malnutrition in infancy: changes in intestinal morphology and disaccharidase activities during treatment with total intravenous nutritions or oral elemental diets. Journal of Pediatrics, 87: 695-704.

4. Rossi MT, Lebenthal E, Nord KS \& Fazili RR (1980). Extent and duration of small intestinal mucosal injury in intractable diarrhea of infancy. Pediatrics, 66: 730-735.
5. Goldegard CM \& Vanderhoof JA (1986). Lack of correlation of small bowel biopsy and clinical course of patients with intractable diarrhea of infancy. Gastroenterology, 90: 527-531.

6. Sullivan PB, Lum PG, Northrop-Clews C, Crouce PT, Marsh MN \& Neale G (1992). Persistent diarrhea and malnutrition - the impact of treatment on small bowel structure and permeability. Journal of Pediatric Gastroenterology and Nutrition, 14: 208215.

7. Toccalino H \& O'Donnell JO (1962). Tecnica para la introdución de la sonda Capsula de Crosby en niños. Revista del Hospital de Niños, 12: 29-30.

8. Barbieri D (1971). Mucosa jejunal na má nutrição protéica primária grave da criança. Doctoral thesis, Escola Paulista de Medicina, São Paulo.
9. Shenk EA \& Klipstein FA (1972). A protocol for the evaluation of small bowel biopsies. American Journal of Clinical Nutrition, 25: 1108-1117.

10. Penna FJ, Hill ID, Kingston D, Robertson K, Slaving E \& Shiner M (1981). Jejunal mucosal morphometry in children with and without gut symptoms and in normal adults. Journal of Clinical Pathology, 34: 386-392.

11. Jordan JR (1986). Anthropometric Software Package. Department of Health and Human Service, Public Health Service, Centers of Disease Control, Atlanta, GA.

12. Stanfield JP, Hutt MSR \& Tunicliffe R (1965). Intestinal biopsy in kwashiorkor. Lancet, ii: 519-523.

13. Schnneider RE \& Viteri FE (1972). Morphological aspects of the duodenojejunal mucosa in protein-calorie malnourished children and during recovery. American Journal of Clinical Nutrition, 25: 10921102. 